\title{
EDUCAÇÃO EM DIREITOS HUMANOS - HERANÇA ILUMINISTA NO CONTEXTO DA PÓS-MODERNIDADE
}

\author{
THE IMPORTANCE OF DOCUMENTARY FILM IN STUDENT TRAINING
}

\author{
Deila Marta de Sá \\ Doutorado em Educação \\ Universidade Nove de Julho - UNINOVE \\ São Paulo, SP - Brasil. \\ neilamarta2019@gmail.com \\ Marcos Antônio Lorieri \\ Doutorado em Educação \\ Universidade Nove de Julho - UNINOVE \\ São Paulo, SP - Brasil. \\ lorieri@sti.com.br
}

Resumo: $O$ artigo problematiza aspectos que caracterizam o atual contexto denominado de pósmodernidade e o neoliberalismo, e de como os direitos humanos são referenciados nesse cenário. Defende a proposta de Educação em Direitos Humanos ressaltando aproximações entre os ideais iluministas originários e os princípios que orientam esta proposta educacional que se opõem às ideias de uma razão instrumental. Explicita o entendimento da EDH como prática pedagógica fundada em atividades que pretendem o desenvolvimento de uma cultura que valorize os direitos humanos, não na perspectiva de uma razão instrumental, mas no sentido de uma formação que promova reflexão e atitudes dos educandos rumo ao processo de humanização na defesa desses direitos - uma formação educativa integral como pretendiam os ideais educativos do Iluminismo. Aponta e insiste na necessidade de uma educação voltada ao entendimento e à prática dos direitos humanos.

Palavras-chave: pós-modernidade; educação em direitos humanos; iluminismo.

Abstract: The article discusses aspects that characterize the current context called postmodernity and neoliberalism, and how human rights are referenced in this scenario. He defends the Human Rights Education proposal, emphasizing similarities between the original Enlightenment ideals and the principles that guide this educational proposal that are opposed to the ideas of an instrumental reason. It explains the understanding of $\mathrm{EDH}$ as a pedagogical practice founded on activities that intend to develop a culture that values human rights, not from the perspective of an instrumental reason, but in the sense of training that promotes reflection and attitudes of students towards the humanization process in the defense of these rights - a comprehensive educational formation as the educational ideals of the Enlightenment intended. It points out and insists on the need for an education focused on the understanding and practice of human rights.

Keywords: post-modernity; human rights education; enlightenment.

Para citar - ABNT NBR 6023:2018

SÁ, Neila Marta de; LORIERI, Marcos Antônio. Educação em Direitos Humanos - herança iluminista no contexto da pós-modernidade. Cadernos de Pós-graduação, São Paulo, v. 20, n. 1, p. 268-280, jan./jun. 2021. Disponível em: https://doi.org/10.5585/cpg.v20n1.19031. 
Introdução

No atual contexto social, denominado por alguns teóricos de pós-modernidade, a sociedade globalizada é controlada por uma classe dominante que segue à risca o neoliberalismo, uma forma de capitalismo sem precedentes na história. Estão presentes também novos recursos tecnológicos, úteis e também vistos como instrumentos de controle que influenciam no comportamento das pessoas que vivenciam processos de construção de uma nova mentalidade, de uma formação que não (re)conhece e nem valora positivamente os direitos humanos. Nesse cenário, o senso comum tem uma visão equivocada que descaracteriza e nega esses direitos, bem como o desenvolvimento pleno dos indivíduos em busca de uma formação que vise o desenvolvimento de sua humanidade numa perspectiva de autonomia reflexiva e crítica.

Dentre as estruturas sociais impactadas por essa nova ordem está a educação, concebida como processo responsável pela formação das novas gerações. Vista numa perspectiva crítica, ela engloba a Educação em Direitos Humanos $(\mathrm{EDH})$, prática pedagógica reflexiva que orienta os discentes na proteção desses direitos, uma vez que, diante de um novo cenário sob holofotes de espetáculos midiáticos e cenas de puro sensacionalismo, emerge a urgente necessidade de se refletir sobre qual o lugar do humano na chamada realidade pós-moderna, visto que prevalece na atualidade um crescente descrédito referente às causas sociais e um abandono dos seres humanos em condições de vulnerabilidade.

Com a EDH o que se ambiciona é uma formação que jamais se omita diante do caos estabelecido que leva o homem a ver o seu semelhante como inimigo. É salutar que, no atual contexto, seja valorizada tal proposta educativa, cujas pretensões são de enfrentamento contra tudo o que pretende anular ideias e propostas educativas relativas aos direitos humanos.

Se os sistemas educativos atuais priorizam uma formação voltada quase que exclusivamente para a questão laboral em atendimento às leis mercadológicas, causando um déficit na formação dos discentes, para contrapor-se a essa realidade, a EDH propõe formação que elege o ser humano e seu processo de humanização como essenciais para sua formação.

Esse artigo estrutura-se apontando aspectos significativos do atual contexto (pós-modernidade) e do neoliberalismo, e de como os direitos humanos são referenciados nesse cenário, além de estabelecer aproximações entre os ideais educativos iluministas e a EDH.

\section{Os direitos humanos no contexto neoliberal}

O neoliberalismo, em plena expansão, emergiu com esse formato a partir de 1970. Para Harvey (2008), o neoliberalismo caracteriza-se como práticas político-econômicas que preconizam 
que o bem-estar das pessoas será promovido caso haja o incentivo das capacidades empreendedoras dos indivíduos, bem como a plena valorização dos direitos relativos à propriedade privada e ao comércio e mercado livres. Nesse contexto, o Estado passa a garantir a efetividade da teoria neoliberal assegurando o pleno funcionamento dos mercados e a integridade do mundo monetário. Cabe ao Estado realizar os processos de privatização de suas instituições garantindo ao setor privado a ação sobre os serviços prestados à comunidade, como saneamento, educação, saúde, dentre outros; nesse cenário, as atribuições do Estado se tornam mínimas em relação ao atendimento do que é direito básico das pessoas e cada vez mais essas atribuições se voltam para garantir os "direitos" dos grandes empreendimentos econômicos e de sua lógica lucrativa. As pessoas são vistas como instrumentos na produção de bens lucrativos e para isso devem ser "educadas". As que não se encaixam nesta perspectiva são apenas toleradas quando não abandonadas à própria sorte ou à sua "falta de sorte".

Os reflexos das ações desse sistema são sentidos em diversas áreas e segmentos sociais. Em muitos países, as estruturas institucionais e a soberania do Estado são afetadas, a política do trabalho e seguridade social são modificadas com a perda de direitos dos trabalhadores, as relações humanas e o sentido do bem-estar social adquirem novos matizes cada vez com mais amesquinhamento dos benefícios sociais reservados, no caso, para poucos. Também são realizados vastos investimentos no setor de tecnologias de informação com o propósito de aumentar a capacidade de armazenar, transferir e analisar dados úteis às transações globais, ao entretenimento ou ao uso pessoal para a parcela minoritária dos "produtivos" nesse sistema e para ele. Essa combinação de fatores altera os modos de viver e de pensar das pessoas, criando-se novos hábitos e alterações nas relações sociais; emerge uma nova ética, orientando modos de agir, distinta de referenciais éticos que orientavam sociedades anteriores.

O momento atual destas transformações é denominado por alguns autores de pós-modernidade. Segundo Lyotard (1992, p.119), a pós-modernidade é uma orientação que "corresponde à evolução das interações sociais, onde o contrato temporário suplanta de fato a instituição permanente de matérias profissionais, afetivas, sexuais, culturais, familiares e internacionais; como nos negócios políticos”. Modificam-se as ações humanas no plano individual e social.

Emerge, com essas mudanças, o neoliberalismo, nova versão do capitalismo que dita um modelo de desenvolvimento que influencia as variantes monetárias dos Estados sob seu domínio, impõe novas regras que alteram as práticas produtivas e as relações de trabalho, e exige inéditas adequações no plano cultural as quais provocam retrocessos referentes às conquistas democráticas alcançadas e às práticas da cidadania. Nesse cenário, as condições de existência do homem tornamse prejudicadas substancialmente, porque passam a ter seus valores negados, dentre eles os valores 
do respeito à diginidade humana que envolvem as garantias dos mais diversos direitos próprios de todas as pessoas pelo fato fundamental de serem pessoas

Essas novas tendências são sentidas também no comportamento humano, sobretudo na esfera política. Sobre esse conjunto de tendências, diz Severino (2010, p. 155) que ele "subverte, também, a vontade, impedindo o exercício de sua liberdade, não deixando que o homem pratique sua formação do cidadão, ou seja, aquele que pode agir livremente na sociedade de iguais" (SEVERINO, 2010, p. 155). Completando esse quadro, estabelece-se um quadro de injustiças sociais, não garantindo ao ser humano as condições objetivas mínimas de vida, cujas ausências acabam por favorecer condições de manipulação que inteferem na constituição da subjetividade das pessoas, desestruturando-as quanto aos valores, conduzindo-as a um profundo niilismo e descrença na capacidade de gerar projetos alternativos para desfazer essa realidade, ocorrendo assim uma "degradação no mundo técnico e produtivo do trabalho, de opressão, na esfera da vida social e de alienação, no universo cultural.” (SEVERINO, 2010, p. 155). Os indivíduos, nesse cenário, agem por impulso, praticam ações que desafiam a imaginação e o bom senso, colocam-se na posição de julgadores da conduta alheia: julgam, condenam, matam. Na nova ordem, emerge um novo irracionalismo que se coloca como hostil aos valores humanos que priorizam uma vida digna. Tais retrocessos alteram e prejudicam as relações humanas, sobretudo no universo dos direitos sociais com destaque para a crescente onda que atinge ferozmente os direitos humanos também subjugados pela ideologia neoliberal. No quadro de crescente negação dos valores democráticos, os direitos humanos sofrem constantes ataques resultando numa desvalorização deles no âmbito das diversas sociedades.

São vários os fatores geradores do processo de desvalorização dos direitos humanos e muitos estão relacionados às significações atribuídas a esses direitos. Para muitos, os direitos humanos são vistos como noções estagnadas, elitistas, fragmentadas ou burocráticas, como indica Carbonari (2009). Explica o teórico que é corriqueiro o discurso midiático de que os direitos humanos são úteis somente para proteger bandidos; ou o seu oposto, tais direitos representam a obra-prima da humanidade: nos dois polos reside a ideia de estagnação, pois ambas como que petrificam uma ideia que deve ser dinâmica ou processual.

As noções elitistas descaracterizam os direitos humanos, quando estes são vistos como matéria apreciada somente por especialistas não constando, assim, na pauta de discussão daqueles considerados "comuns". Prevalecem as noções fragmentadas quando se desconsidera o princípio da interdependência e integralidade entre os direitos humanos ao se priveligiar um direito em detrimento de outro. Isso resulta em tratamento diferenciado na reivindicação desses direitos; pois, ao reconhecerem uns, desrespeitam-se outros. 
Aspectos burocráticos também emperram a não efetivação dos direitos humanos quando os procedimentos provocam o protelamento de providências e quando não são efetivamente organizadas as ações do poder público e da sociedade na reivindicacão e proteção de tais direitos.

A efetivação dos direitos humanos importa na adoção de um discurso contra hegemônico como uma exigência nos contextos democráticos e com plena realização da cidadania ativa. A concretização desses direitos retoma a significação de luta, reivindicação ou reconhecimento, em sentidos diversos. Salienta Carbonari (2009) que lutar pelos direitos humanos tem a ver com territorialidade e temporalidade, indicando que a prestação e garantia de tais direitos relaciona-se a ações urgentes em locais e tempo específicos, pois elas não podem ser deslocadas no espaço ou em tempos diferenciados; os direitos devem ser exigidos no local e tempo de sua ocorrência.

Lutar também significa reconbecimento do indivíduo como gente, ou seja, a identidade de ser humano, de ser gente, o torna detentor de direitos humanos. Além disso, a afirmação dos direitos humanos também refere-se à universalidade de demandas, visto que, atentar a um caso específico em conformidade com exigências justas no reconhecimento de tais direitos, configura-se como ação importante para toda a sociedade, uma vez que derivará disso o caráter universal dos direitos humanos transformados, posteriormente, em políticas públicas.

A efetividade dos direitos humanos impõe também a presença dos envolvidos na luta, ou seja, quem sofre atentado contra os seus direitos é levado a expor-se como vítima para exigi-los, como também a exigir reparação da agressão sofrida; e, por fim, lutar também está associado à compreensão da expressão construção de sujeitos, porquanto, no contexto atual onde predomina o individualismo, a luta pelos direitos humanos leva o indivíduo ao encontro de sua subjetividade transformando-o em um ser capaz de encontrar sua humanidade representada em ações libertadoras de toda forma de opressão e de injustiças.

Compreender o porquê da não efetivação da garantia dos direitos humanos no cenário atual, ou quais os atributos conferidos a esses direitos, vincula-se ao processo educativo cujo objetivo está na promoção, proteção e efetivação dos referidos direitos; processo esse envolvido no que se denomina de Educação em Direitos Humanos (EDH): uma proposta pedagógica emancipadora cujo objetivo é gerar empoderamento coletivo e individual a respeito dos direitos humanos, ao mesmo tempo em que visa também neutralizar as práticas individualistas as quais promovem o isolamento entre as pessoas e, por consequência, o enfraquecimento desta luta.

Daí a necessidade de ampliar a compreensão do que seja esta proposta educativa e como ela se opõe às características mencionadas da pós-modernidade e do neoliberalismo. 


\title{
A Educação em Direitos Humanos (EDH)
}

A Educação em Direitos Humanos (EDH) orbita em torno desses direitos e em sintonia com os princípios fundamentais que os alicerçam, mantendo em harmonia os pressupostos de interdependência, indivisibilidade e universalidade entre eles. Oferece orientações para atividades de natureza prática no universo cultural dos educandos em diversos níveis. Trata-se de proposta do Poder Público que adota o conceito de EDH constante do Plano de Ação do Programa Mundial para Educação em Direitos Humanos da UNESCO afirmando-a como:

\begin{abstract}
Um conjunto de atividades de educação, de capacitação e de difusão de informação, orientado para a criação de uma cultura universal de direitos humanos. Uma educação integral em direitos humanos não somente proporciona conhecimentos sobre os direitos humanos e os mecanismos para protegê-los, mas, além disso, transmite as aptidões necessárias para promover, defender e aplicar os direitos humanos na vida cotidiana das pessoas. A educação em direitos humanos promove as atitudes e o comportamento necessários para que os direitos humanos para todos os membros da sociedade sejam respeitados (UNESCO, 2012, p.3).
\end{abstract}

A Educação em Direitos Humanos não se restringe a uma aprendizagem cognitiva sobre eles, mas almeja que todas as pessoas envolvidas nesse processo alcancem um desenvolvimento emocional e social de modo interativo entre a instituição educativa e a sociedade. O que se pretende é o desenvolvimento de atividades de capacitação e difusão de informação destinadas a formar atitudes visando à promoção e defesa dos direitos humanos. Nesse sentido, o Programa Mundial de Educação em Direitos Humanos (PMEDH), de autoria da UNESCO e do Alto comissariado da ONU para os direitos Humanos, elencou as principais finalidades da EDH. São elas:

\footnotetext{
(a) fortalecer o respeito aos direitos humanos e às liberdades fundamentais; (b) desenvolver plenamente a personalidade humana e o sentido da dignidade do ser humano; (c) promover a compreensão, a tolerância, a igualdade entre os sexos e a amizade entre todas as nações, os povos indígenas e os grupos raciais, nacionais, étnicos, religiosos e linguísticos; (d) facilitar a participação efetiva de todas as pessoas em uma sociedade livre e democrática na qual impere o Estado de Direito; (e) fomentar e manter a paz; (f) promover um desenvolvimento sustentável centrado nas pessoas e na justiça social (ONU, 2020).
}

Direitos humanos, na sua concepção internacional, são os direitos de que qualquer ser humano é detentor e que estão instituídos em declarações, convenções ou pactos internacionais e atendem as exigências da dignidade humana. Callo (1977) salienta que os direitos humanos são universais (referem-se a todas as pessoas), congênitos (são inerentes a todo ser humano), absolutos (devem ser respeitados por todas as pessoas), e necessários (são ontológicos, fazem parte da própria natureza do ser humano). Esses direitos jamais podem ser negociados, renunciados, separados uns dos outros, ou sofrer atentados, ou ainda perderem-se por decurso de prazo; portanto, tais direitos são, respectivamente, inalienáveis, irrenunciáveis, indissociáveis, invioláveis e imprescritíveis. 
Segundo Perez Luño (1991, p.48), os direitos humanos representam “um conjunto de faculdades e instituições que, em cada momento histórico, concretizam as exigências de dignidade, liberdade e igualdade humanas, as quais devem ser reconhecidas positivamente pelos ordenamentos jurídicos, nos planos nacional e internacional”. Para Alexandre de Moraes, os direitos humanos configurados como direitos fundamentais, estruturam-se em torno da dignidade humana e exigem proteção da figura estatal; eles são representados por um conjunto de "direitos e garantias do ser humano que tem por finalidade básica o respeito a sua dignidade, por meio de sua proteção contra o arbítrio do poder estatal e o estabelecimento de condições mínimas de vida e desenvolvimento da personalidade humana." (MORAES, 1998, p.39).

O princípio orientador dos direitos humanos é a dignidade humana presente em todas as pessoas e em cada pessoa individualmente. A dignidade humana é definida como a

\begin{abstract}
qualidade intrínseca e distintiva reconhecida em cada ser humano que o faz merecedor do mesmo respeito e consideração por parte do Estado e da comunidade, implicando, neste sentido, um complexo de direitos e deveres fundamentais que assegurem a pessoa tanto contra todo e qualquer ato de cunho degradante e desumano, como venham a the garantir as condições existenciais mínimas para uma vida saudável, além de propiciar e promover sua participação ativa e corresponsável nos destinos da própria existência e da vida dos seres humanos, mediante o devido respeito aos demais seres que integram a rede da vida. (SARLET, 2003, p. 73).
\end{abstract}

No plano legal, a dignidade humana está presente na Constituição Federal de 1988 como um de seus fundamentos (Art. $1^{\circ}$ ); os direitos humanos comparecem como um dos objetivos (Art. $3^{\circ}$ ) e como um dos princípios (Art. $4^{\circ}$ ) da República Federativa do Brasil. No Art. $5^{\circ}$ da CF/88, os direitos humanos são citados como os Direitos e Garantias Fundamentais referentes aos Direitos e Deveres Individuais e Coletivos, e aos Direitos Sociais.

A EDH apresenta-se com duplo anseio: a) defender os direitos humanos por intermédio da educação numa indicação de que todos os elementos que envolvem os processos de aprendizagem, como projetos, planos de estudo, material didático, métodos pedagógicos e a capacitação dos que trabalham com educação sejam canalizados para um aprendizado acerca dos direitos humanos; b) concretizar práticas de direitos humanos em instituições educativas por meio de uma vivência cultural com a participação de todos envolvidos no processo.

\title{
Os ideais educativos iluministas e a EDH
}

Busca-se, a seguir, indicar como diversos pressupostos da EDH originaram-se nos princípios iluministas tendo-se por referência ideias como as de Kant (final do Século XVIII e início do XIX) e de Habermas (Séculos XX e XXI).

O Iluminismo caracterizou-se por um momento em que se enfraqueceu o poder da nobreza e do clero e a organização social ocidental da época que se sustentava em fundamentos religiosos 
e valores medievais que foi substituída pela organização social preconizada pela burguesia a qual iniciava seu processo de controle econômico e político da sociedade. Nesse cenário, os iluministas defendiam abertamente a ciência e a racionalidade crítica, minimizando as práticas contemplativas do pensamento e privilegiando as atividades da ciência com a intenção de promover melhorias na vida dos indivíduos por intermédio de uma qualificação educativa que os habilitasse à ação no meio político e econômico: a razão, significando uma ideia de progresso, passou a ser uma necessidade.

A educação passou a ser vista como força emancipadora e capaz de resgatar a capacidade racional autônoma do homem tornando-o capaz de desenvolver plenamente suas potencialidades racionais. Ela ofereceria uma formação integral ao ser humano encaminhando-o ao exercício de reflexão e ação para dirimir questões da humanidade: a razão seria o alicerce do conhecimento humano. A educação iluminista assumia então o papel de formar esse ser humano.

A razão iluminista desejava fazer as sociedades plenamente cultas com predominância dos valores éticos e conduzindo os indivíduos para boas ações a partir de valores como justiça e igualdade. Os ideais iluministas pregavam que a educação deveria ser laica, pública, gratuita e de acesso universal. A razão era concebida como um valor supremo, pois, além de mostrar aos homens como usufruir da natureza, também afiançaria a sociedade rumo a um futuro que garantisse o bem-estar de todos. O projeto educativo moderno ancorado na racionalidade e no progresso garantiria à humanidade a passagem de um estágio menos desenvolvido para outro mais pleno. Segundo Goergen (2005), o propósito iluminista na modernidade era possibilitar ao homem, conscientizado de seu saber racional, desvendar os segredos da natureza e utilizá-la para garantir sua sobrevivência, além de encontrar soluções para questões que o impediam de ascensão rumo ao bem-estar social.

Para Kant (2020), um dos idealizadores do projeto educativo iluminista, a educação deveria formar um homem crítico e capaz de julgar os seus próprios valores, visto que era necessário mudanças no seu comportamento: ele deveria sair do estágio de sua menoridade compreendida como "a incapacidade de se servir do entendimento sem a orientação de outrem.” (KANT, 2020, p. 1). Para ele, era necessário que o homem assumisse a responsabilidade do seu próprio processo educativo, embora reconhecesse que passar para a maioridade fosse um processo difícil, uma vez que era cômodo ser menor e não ter que enfrentar e posicionar-se diante do mundo. O homem seria capaz de pensar por si mesmo se fosse proporcionado a ele a oportunidade para tal: com isso, seu estado de maioridade se concretizaria: "Mas é perfeitamente possível que um público a si mesmo se esclareça. Mais ainda, é quase inevitável, se para tal lhe for concedida a liberdade” (KANT, 2019, p. 2). É imprescindível conduzir o homem à liberdade para proporcionar-lhe a condição de ser pensante: "Mas, para esta ilustração, nada mais se exige do que a liberdade; e, claro está, a mais 
inofensiva entre tudo o que se pode chamar liberdade, a saber, a de fazer um uso público da sua razão em todos os elementos. (KANT, 2019, p. 2).

O conhecimento retiraria o homem da condição de ser passivo e, por meio de uma razão livre com o uso da ciência e da técnica, o indivíduo seria capaz de dominar da natureza e ter a capacidade de organizar o mundo e, dessa maneira, a educação passaria a ser essencial à vida humana. "O homem não pode tornar-se um verdadeiro homem senão pela educação. Ele é aquilo que a educação dele faz.” (KANT, 1996, p. 15), pois, "O homem é a única criatura que precisa ser educada. Por educação entende-se o cuidado de sua infância (a conservação, o trato), a disciplina e a instrução com a formação.” (KANT, 1996, p. 11). A formação é:

1) Negativa, isto é, disciplina, a qual impede os defeitos; 2) positiva, isto é, instrução e direcionamento $\mathrm{e}$, sob este aspecto, pertence à cultura. $\mathrm{O}$ direcionamento é a condução na prática daquilo que foi ensinado. Daqui nasce a diferença entre o professor, o qual é simplesmente um mestre, e o governante, o qual é um guia. O primeiro, ministra a educação da escola; o segundo, a da vida. (KANT, 1996, p. 30-31). (Itálicos no original).

A formação, para Kant, inclui a disciplina que é negativa porque "impede ao homem de desviar-se do seu destino, de desviar-se de sua humanidade” (idem, p. 12); e inclui a instrução ou a cultura - "pois que assim pode ser chamada a instrução" (idem, p. 16). "Quem não tem cultura de nenhuma espécie é um bruto; quem não tem disciplina ou educação é um selvagem.” (idem, p. 16). A cultura abrange instrução (conhecimentos) envolvendo um trabalho professoral e de direção, de governança ou de guia para a vida. Para Kant a educação é constituidora da humanidade no humano. Contudo, as ideias da educação iluministas não se concretizaram totalmente no contexto da modernidade devido à interferência da ideologia burguesa. Goergen (2005) afirma que o paradigma de conhecimento da modernidade, considerado seguro, acabou por atribuir ao conhecimento uma dimensão de utilidade e poder. O ideal de uma educação pública, universal, laica que ofereceria uma educação integral para uma atuação do ser humano visando à justiça social foi abandonado em nome de uma formação unilateral em atendimento à produtividade econômica e eficiência no mundo industrial: a educação de matiz universal passa a ser uma educação de classe. Mühl afirma que o projeto iluminista como

identidade genérica, pela qualificação técnico-científica, ética, estética, política, econômica e pedagógica de todos os membros da sociedade defendida pelos iluministas, cede lugar a uma formação diferenciada, elitista para os grupos sociais privilegiados e apenas elementar para os demais segmentos sociais. (MÜHL, 2008, p 117).

Os estudos sobre os ideais iluministas centrados na razão geram interpretações críticas na contemporaneidade. Uma dessas interpretações é a de Rouanet (1998) que vê duas vertentes decorrentes da concepção iluminista da razão: uma que deforma o ideário iluminista e outra que afirma a essência do movimento. A primeira seria, nas suas palavras, a razão louca e, a segunda, a razão sábia. Para ele, a razão louca não adotaria um posicionamento questionador e abdicaria das 
prerrogativas críticas, inclusive da prerrogativa de desmascarar a pseudo-razão; silenciaria diante dos irracionalismos sociais, servindo às armadilhas do poder e à supremacia dos desejos, caracterizando-se como uma razão definida com traços narcísicos, bem ao gosto dos valores presentes na pós-modernidade e mostrando-se, simultaneamente, ingênua e arrogante. A razão sábia identificaria e criticaria a irracionalidade presente no próprio sujeito cognitivo e nas instituições externas, assim como nos discursos que se pretendem racionais - as ideologias (ROUANET,1998).

Habermas, filósofo contemporâneo, analisa as relações entre os seres humanos e o papel da razão nessas relações. Em sua obra, Teoria da Ação Comunicativa (2012), elege a racionalidade como tema central e afirma que é possível uma nova configuração dela, vendo-a, por um lado como racionalidade instrumental e, por outro, como racionalidade comunicativa. Esta última se coloca como forma de enfrentamento das reduções cognitivo-instrumentais da razão. Ele propõe rever o papel da razão buscando afastar dela o sentido do determinismo instrumental, afirmando que "a teoria da ação comunicativa se propõe a investigar a 'razão' inscrita na própria prática comunicativa cotidiana e reconstruir, a partir da base de validade da fala, um conceito não reduzido de razão." (HABERMAS, 1989, p. 506).

A razão, nesse novo entendimento, passa a ser concebida como algo que se manifesta a partir da interação entre os seres humanos através de uma linguagem e de um saber confiável que emerge dessa interação. Dessa maneira, a racionalidade se manifesta quando, através da interação, obtivermos o conhecimento sobre algo, quando esse conhecimento nos motivar a agir e quando nos pronunciarmos sobre ele, tornando-o útil para a defesa de nossas ações, crenças e valores. Desse modo, a racionalidade apresenta-se com um caráter epistemológico ou cognitivo, teleológico e comunicativo e construída na interação linguística quando os indivíduos se encontram para debater sobre e para dar validade a um conhecimento.

A teoria de Habermas tem por base o encontro entre os seres humanos que debatendo temáticas relevantes à sua própria existência, pronunciam-se argumentativamente e buscam procedimentos e ações para dirimir os conflitos originados na sociedade. Nesse caso, os sujeitos passam a ter domínio sobre o objeto ou tema discutido e sobre a ação de controle da realidade.

A EDH, em seus princípios, assemelha-se aos postulados defendidos por Habermas, visto que orienta para o encontro daqueles que refletem e reivindicam os direitos humanos a partir de pronunciamentos argumentativos e das tomadas de decisão sobre de que modo é viável pleitear a proteção de tais direitos.

Os ideais da educação iluminista, na direção da razão sábia, ou da razão comunicativa, encontram-se, também, na proposta da EDH. Segundo as Diretrizes Nacionais para a Educação em Direitos Humanos (2012), essa modalidade educativa tem por meta uma formação que oriente na 
promoção de uma educação que reafirme os valores democráticos e a prática da cidadania visando à efetivação de um pleno estado democrático de direito. As Diretrizes informam ainda que a instituição educativa, concebida como entidade social, tem o dever de zelar pela diversidade cultural, individual ou coletiva, e a obrigação de formar cidadãos plenos, conscientes de seus direitos e deveres e capazes de interferir nos projetos políticos, sociais, educativos e culturais do país. Nesse sentido, a EDH torna-se guardiã dos princípios que protegem o ser humano e seus direitos elencados na Constituição Federal de 1988. Esta Carta Magna preconiza o caráter da universalidade da educação brasileira, o estado laico, como também a gratuidade da educação e a responsabilidade de Estado na sua efetivação, princípios análogos ao modelo pleiteado pela educação iluminista.

Os valores democráticos constituem a base da EDH. A essência da democracia reside na proteção dos direitos humanos, pois sem o reconhecimento desses direitos e o devido respeito a eles manifestado em ações concretas, não há democracia.

Para a existência de um estado democrático de direito, é imprescindível que haja normas capazes de regulamentar as relações humanas para garantir a convivência de grupos sociais diversos, os direitos políticos e ações interventivas relacionadas a questões econômicas como forma de garantir as condições mínimas de existência de todas as pessoas nas esferas biológica, psíquica e social. A democracia significa, portanto, espaço de concretização e ampliação dos direitos humanos e somente em sociedades democráticas será possível a prática desses direitos.

A razão sábia de que fala Rouanet, cujo princípio pauta-se na reflexão crítica, bem como a teoria da ação comunicativa de Habermas, fundada no encontro entre os seres humanos que debatem, deliberam e buscam ações efetivas, somam-se às bases da EDH, já que o princípio dessa educação é não pretender apenas conhecimentos específicos sobre os direitos humanos ou apenas buscar mecanismos visando à sua proteção. É isso também e muito mais: é buscar desenvolver nos educandos processos argumentativos, atitudes e aptidões necessários para que eles possam proteger, promover, defender e aplicar os direitos humanos na vida cotidiana. Essas ações implicam numa abordagem histórico-crítica sobre os direitos humanos, os quais passam a ser a base na construção de um projeto social justo com as novas gerações, auxiliando-as a assumirem o papel de atores sociais, responsáveis e comprometidos com a concretização desses direitos. Assim, exercerão a cidadania ativa como protagonistas e participando no desenvolvimento de uma sociedade igualitariamente justa, pois, desse modo, estarão lutando para a garantia dos direitos humanos de todas as pessoas e em especial daqueles grupos marginalizados socialmente e defendendo o cumprimento da equidade na distribuição dos recursos econômicos e culturais os quais devem ser destinados para todos e não para minorias privilegiadas. 


\section{Considerações Finais}

A atual maneira de conceber a razão não pode ser aquela do século XVIII, cujo entendimento não conseguia identificar os limites internos e externos da racionalidade. Que a razão, no contexto atual, seja reconhecida como reflexiva, crítica, sábia, ou a que está presente na teoria da ação comunicativa, devendo constar no cotidiano formativo das instituições educativas. No contexto da $\mathrm{EDH}$, a razão terá sempre por meta o dever de formar seres humanos tornando-os capazes de crítica e autocrítica, de desenvolver cidadania ativa motivando-os a esquadrinhar a legislação e os preceitos das instituições e estar sempre em alerta para desmascarar os discursos, teorias e ideologias que insistem em descaracterizar e anular os direitos humanos. Não basta postular a necessidade da razão nos sentidos citados, é necessário demonstrar que ela é viável nas condições contemporâneas. A racionalidade crítica torna-se essencial para a transformação da sociedade e pode perfeitamente representar uma ideia de progresso na concepção de melhores condições de vida para os seres humanos a partir das práticas desenvolvidas na EDH.

\section{Referências}

BRASIL. Constituição (1988). Constituição da República Federativa do Brasil. Disponível em: http://www.planalto.gov.br/ccivil_03/constituicao/constituicao.htm. Acesso em out. 2020.

BRASIL. Lei 9.394/96, de 20 de novembro de 1996. Estabelece as diretrizes e bases da educação nacional. S Disponível:< http://portal.mec.gov.br/arquivos/pdf/ldb.pdf > . Acesso em: 12 jun. 2020 .

BRASIL. Parecer CNE/CEB n. 11/2012. Diretrizes Curriculares Nacionais para a Educação Profissional Técnica de Nível Médio. MEC/CNE, Brasília, 2012. http:/ / portal.mec.gov.br/index.php?option $=$ com_docman\&view $=$ download\&alias $=11663$ rceb006-12-pdf\&category_slug=setembro-2012-pdf\&Itemid=30192.

CALLO, J. I.H. Panorama de los Drechos Humanos. Buenos Aires: Editora da UBA, 1977.

CANDAU, Vera Maria Et al. Educação em direitos Humanos e formação de professores (as). São Paulo: Cortez, 2013.

CARBONARI, Paulo César. Fran₹. Hinkelammert: utopia crítica, libertação e direitos bumanos. In: CARBONARI, Paulo César (Org.). Sentido filosófico dos direitos humanos: leituras de pensamento contemporâneo 2, Passo Fundo: IFIBE, 2009.

GOERGEN, Pedro. Pós-modernidade, ética e educação. 2. Ed. Revista - Campinas, SP. Autores Associados, 2005. - ( Coleção polémicas do nosso tempo; 79)

HABERMAS. Y. La lógica de la acción comunicativa: complementos y estudios previos. Madrid: Cátedra, 1989.

HABERMAS, Y. Teoria da ação comunicativa. São Paulo: Martins Fontes, 2012. Vol. I e II. 
HARVEY, David. O neoliberalismo, história e implicações. Tradução Adail Sobral Maria Stela Gonçalves. Edições Loyola, São Paulo, Brasil, 2008. Disponível em: https://www.uc.pt/feuc/citcoimbra/Harvey2008. Acesso: out. 2020.

KANT, Immanuel. Sobre a pedagogia. Trad. Francisco Cock Fontanella. Piracicaba, SP: Editora Unimep, 1996.

KANT, Immanuel. Resposta à pergunta: Que é o iluminismo? Tradutor: Artur Morão. Disponível em: http://www.lusosofia.net/textos/kant_o_iluminismo_1784.pdf. Acesso em: set. 2020.

LYOTARD, Jean-François. O pós-moderno. Rio de Janeiro, José Olympio, 1988. $3^{a}$ edição. Trad. Ricardo Corrêa Barbosa. Disponível em: https://monoskop.org/images/b/bf/Lyotard_JeanFrancois_O_pos-moderno_3a_ed.pdf. Acesso em: 14 out. 2020.

MORAES, Alexandre de. Direitos humanos fundamentais. São Paulo: Atlas, 1998.

ONU. Programa Mundial para a Educação em Direitos Humanos. Disponível em: https://unesdoc.unesco.org/ark:/48223/pf0000232922. Acesso em: 25 out. 2020.

PEREZ LUÑO, Antonio Enrique. Derechos Humanos, Estado de Derecho y Constitución. 4. Ed., Madrid, Tecnos, 1991, p 48.

PINTO, F. Cabral. A formação humana no projecto da modernidade. São Paulo: Instituto Piaget, 1996.

ROUANET, Sérgio Paulo, As razões do iluminismo. São Paulo: Companhia das Letras, 1998.

SARLET, I. W. Dignidade da pessoa humana e direitos fundamentais na Constituição Federal de 1988. 9. ed. rev. atual. Porto Alegre: Livraria do Advogado, 2011.

SAVIANI, D. A nova Lei da Educação: LDB, limite, trajetória perspectivas. 8 ed. São Paulo: Autores Associados, 2003.

SEVERINO, Antonio Joaquim. Desafios da formação bumana no mundo contemporâneo Revista de Educação Puc-Campinas, Campinas, n.29, p.153-164, jul./dez., 2010. Disponível em http://periodicos.puc-campinas.edu.br/seer/index.php/reveducacao/article/view/50/39. Acesso em: 20 set. 2020.

UNESCO. Plano de ação: Programa Mundial para Educação em Direitos Humanos. Primeira fase. Brasília, 2012. Disponível em: http://www.dhnet.org.br/dados/textos/edh/br/plano_acao_programa_mundial_edh_pt.pdf. Acesso em: out. 2020. 